\title{
Nature and Effectiveness of Psychological Interventions Provided to Rape Survivors in Selected Post-Rape Care Centres in Kenya
}

\author{
Lucy Jemutai Kibet \\ PhD, Catholic University of Eastern Africa (CUEA); P. O. Box 908-30100, Eldoret, Kenya
}

\section{*Corresponding Author}

Lucy Jemutai Kibet

\section{Article History}

Received: 12.10 .2020

Accepted: 28.10 .2020

Published: 06.11.2020

\begin{abstract}
The study sought to find out the effectiveness of psychological interventions provided to rape survivors in selected post-rape care centres in Nairobi and Uasin-Gishu Counties in Kenya. The study was guided by the Crisis theory by Caplan. The study utilized a descriptive survey research design. The target population included rape survivors aged 10-45 years who had attended at least three psychological interventions while the key informants were the counsellors in these centres. Purposive sampling was used to obtain a sample of 44 rape survivors and 9 key informants from the two selected post-rape care centres. Consent forms were issued to the adult participants (18 years and above) to sign. The participants (aged 10-17years) were given assent forms after they were made to understand about the purpose of the research in the presence of their parents or guardians. The data was collected by use of structured questionnaires developed by the researcher. The researcher assisted the primary school children and illiterate participants using Kiswahili translation. The data collected was analysed using descriptive and inferential statistics. Most of the rape survivors were given individual counselling, group counselling, follow-up counselling and support group. Only 63.6\% received legal services. The findings revealed that psychological interventions were generally effective. The combined perceived usefulness of psychological interventions was relatively high $(M=3.3)$. There was also a significant reduction of combined mean of psychological effects $(\mathrm{M}=3.7)$ before treatment compared to after treatment $(\mathrm{M}=1.5)$, and a statistical significant difference between the mean severity level of the psychological effects experienced before treatment $(\mathrm{M}=3.742, \mathrm{SD}=1.2777)$ compared to after treatment $(\mathrm{M}=1.513, \mathrm{SD}=0.4958)$. The study thus concluded that there was significant reduction of psychological effects after treatment. Based on the study findings and conclusion, it is recommended that, to improve the overall effectiveness of psychological interventions provided to rape survivors in postrape-care centres, there should be a review of the interventions provided to ensure adequate provision especially of the legal services, follow-up and family counselling.
\end{abstract}

Keywords: Psychological Interventions, Rape Survivors, Post-Rape Care Centres, Kenya.

\section{INTRODUCTION}

Rape entails the use of threat, physical force, intimidation or other ways by a person to obtain sexual relations with a person against her/his will, and causing her/him to be in a state of psychological disequilibrium. Most rape survivors experience short and long-term psychological disturbances [1]. The immediate psychological disturbances caused by rape include feelings of helplessness, self-blame, anxiety, fear, shock, denial, numbness and confusion [2]. For some rape survivors, many of these psychological effects resolve within a short period, but, for others, these effects continue for a longer period leading to post-traumatic stress disorder (PTSD) [3]. PTSD is commonly associated by phobias, sexual dysfunctions, anxiety, alcohol and drug abuse, high-risk sexual behaviours, depression and suicidal ideations.

Rape is also associated with a high risk of contracting sexually transmitted infections such as HIV/AIDS, and hepatitis B and C, which increases the psychological effects to the rape survivor [4]. These disorders commonly make survivors withdraw from loved ones while children acquire developmental trauma disorder [2]. In most cases, the effects of rape are less understood, which may lead to stigmatization and psychological problems to the rape survivors, families

Copyright $\odot 2020$ The Author(s): This is an open-access article distributed under the terms of the Creative Commons Attribution 4.0 International License (CC BY-NC 4.0) which permits unrestricted use, distribution, and reproduction in any medium for noncommercial use provided the original author and source are credited. 
and community [5]. As such, family members of rape survivors need to be enlightened on the importance of their support in the care of the survivor's adherence to psychological interventions and other treatments. Psychological impacts of rape may be reduced with the provision of psychological interventions and psychosocial support to rape survivors at post-rape care centres [6].

One of the ways to address such impacts of rape on survivors was the establishment of post-rape care centres. Most post-rape care centres have components focusing on health care responses, legal support, psychological interventions as well as community-based efforts and actions to prevent other incidences. In many developed societies across the world, for example in USA, Europe and Australia, effective psychological approaches used to treat adult rape survivors involve various adaptations of cognitive behavioural interventions provided in group therapies and one-on-one counselling [7]. Effective approaches for children include the establishment of safety and competence art therapy, addressing traumatic re-enactments and integration and mastery of mind and body [8]. In the first months of post-rape care, the focus of therapy and prevention of three main chronic effects associated with rape: PTSD, depression and anxiety is managed [2]. Most therapies for chronic psychological problems have been implemented in the developed world by use of multimodal counselling sessions for a long-term with a psychologist.

\section{Interventions Provided to Rape Survivors}

Many of the harmful and lasting psychological effects of rape could be prevented or minimized with structured interventions along with provision of psychological interventions within post-rape care programmes [9]. Whilst many survivors recover spontaneously from the psychological aftermath of rape, the identification and treatment of psychopathology could be of great benefit to them. According to Population Council [10], comprehensive post-rape care for rape survivors include psychological interventions, treatment of physical injuries, pregnancy testing and emergency contraception, TI prophylaxis, HIV diagnostic testing and counselling. Post-exposure prophylaxis, collection of forensic evidence, documentation and provision of referrals to initiate prosecution are also crucial services provided to rape survivors. The Population Council suggests that there is a need to establish strong links between the police and health facility and non-governmental organisations (NGOs) so that incidents of rape can be referred in either direction.

Cognitive behaviour therapy treatment for PTSD among rape survivors is one of the most tested therapies in the scientific literature. Cognitive-behavioural interventions generally include cognitive restructuring exercises and exposure techniques [7]. Effective approaches for children include provision of safety, addressing traumatic re-enactments and art therapy [8]. Early interventions for helping individuals through their immediate reactions to assault could reduce or even prevent more severe psychological distress [11]. An early intervention is a one-session administered to rape survivor prior to hospital forensic examination [12]. A study by Atkinson [13] found that account-making of events, which includes descriptions, explanations and predictions of future events, is associated with reduction of effects and facilitated post-rape readjustment.

According to Faugno and Speck [14], some rape survivors may find it difficult to cope on their own and may develop chronic psychological effects. All rape survivors should be given the option of long-term psychological intervention. Combination therapies involving psychotherapy and medications are often used [15]. The US National Comorbidity Survey indicates that $80 \%$ of those suffering from PTSD would have co-morbid psychopathologies ranging commonly from excessive alcohol and/or drug consumption to affective and anxiety disorders [16]. Therefore, therapies must be tailored to individual circumstances and needs of each rape survivor.

Unfortunately, the provision of comprehensive referral services in resource-poor settings is difficult [17]. Over the past decade, many African countries have begun to recognize the importance of both preventing rape and responding to the needs of rape survivors at a national level [18]. Some countries in Africa, for instance South Africa, have developed one-stop-shop located within or connected to a hospital to enable survivors to access medical, legal, psychosocial, counselling, case management and referrals on site [19].

The components of the clinical evaluation, which include forensic examination, specimen collection, analysis and documentation, act as a vital link between health care and the judicial system. The examination includes establishing the background of the survivor, taking the history of the occurrence, a medical history and a full body physical examination that is efficiently documented [20]. Care is taken to minimise additional trauma by providing initial comfort, counselling and a full explanation of the logic and process of the procedures. A co-ordinated approach to delivering medical services is advised to eliminate the need for referrals and delay [21]. However, these post-rape care programmes administer limited interventions that comprise mainly immediate medical care and forensic examination. The psychological needs of rape survivors are often not considered, even in settings that provide medical services [6]. Psychological interventions are mostly overlooked, yet both formal and informal psychological interventions are effective in reducing the long-term psychological effects of rape on rape survivors. 
In resource-poor settings, such as Kenya, most efforts to strengthen responses to rape survivors have so far focused on the training of staff based in hospitals or crisis centres [22]. The staff administers limited services such as immediate medical care, a forensic examination before referring patients to social workers if the latter are available. In Kenya, some post-rape care centres have formal psychological intervention, integrated into existing health systems designed specifically for HIV services, that provides psychosocial support to rape survivors and their partners [23]. Some of the services includes individual counselling, support groups, 24-hour hotline and informal counselling services (women groups and faith-based groups) in the community.

Kilonzo, Theobald, Nyamato, Ajema, Muchela, Kibaru and Rogena [24] carried out a situational analysis of the post rape services in Kenya. The study revealed the lack of standards, policy, coordination and delivery mechanisms for survivors of sexual violence. Referral systems for survivors of rape were also found to be lacking in most of the facilities visited. These findings led to the development of an integrated model for delivery of post-rape care services in Kenya. However, while Kilonzo et al., provided useful information with regard to post-rape services available at that time, there was still limited evidence regarding the effectiveness of psychological interventions offered to rape survivors.

\section{Statement of the Problem}

Incidences of rape have been increasing at an alarming rate in Kenya. This view is supported by many studies carried on the prevalence of rape, which indicate that rape occurs every half hour in Kenya [25, 26]. Despite the high prevalence of rape in Kenya, rape has received insufficient attention from service designers, policy-makers and researchers to recognise that rape causes long-lasting psychological harm [22]. The WHO [9] recognizes the need to strengthen the quality of services offered to rape survivors. There is evidence that psychological interventions play a role in psychological recovery of rape survivors. Comprehensive high-quality post-rape care services have been found to hasten the rate of reduction of psychological effects of rape on survivors [4, 18]. Therefore, the question arises as to whether the psychological interventions provided at post-rape care centres in Kenya are effective. There have been many studies on effectiveness of psychological interventions provided to rape survivors done in USA, Europe and Australia [7], but very little has been done in Africa. In Kenya, few studies have been carried out on the effectiveness of psychological interventions provided to rape survivors at post-rape care centres. This prompted the researcher to undertake the study to ascertain the psychological effects of rape. Based on the study, this paper presents and discusses the research findings on the nature and effectiveness of psychological interventions provided to survivors of rape in selected post-rape care centres in Kenya.

\section{Materials ANd Methods}

The study utilized a descriptive research design, which combined both qualitative and quantitative approaches. The research design was appropriate for the study as the researcher described the mean scores and the significance of associations and significant differences between the various variables and groups. The independent variables were the psychological interventions while the dependent variables were the psychological effects. The study was carried out in post-rape care centres, namely Nairobi Women Hospital (NWH) in the Nairobi County and the Moi Teaching and Referral Hospital (MTRH), in Uasin-Gishu County both in Kenya. The Nairobi Women Hospital was founded in 2001 and the first of its kind in the East and Central Africa region, which focuses on women and children's health care and also attend to male rape survivors. MTRH is the second largest referral hospital in Kenya, which serves as a referral for the Western region of the country. The post-rape care centre at MTRH called Centre for Assault Recovery Eldoret (CARE) was established in 2007. Purposive sampling was used to select the two counties of Nairobi and Uasin-Gishu. These two post-rape care centres were purposively sampled because they are among the well-established centres in Kenya that received relatively large number of rape survivors compared to other centres in the country.

The target population were rape survivors aged 10-45 years and key informants were psychological counsellors at the selected post-rape care centres. According to health records statistics in the two selected centres, Nairobi Women Hospital received an average of two hundred and thirty rape survivors monthly while sixty rape survivors attended Moi Teaching and Referral Hospital [27]. Therefore, a total number of two hundred and ninety rape survivors constituted the target population. The target population of this study were rape survivors who had attended at least three psychological intervention sessions in Nairobi Women Hospital and Moi Teaching and Referral Hospital post-rape care centres. This study population of rape survivors comprised those able to understand and communicate clearly and therefore severely mentally challenged rape survivors were excluded in the sample

New rape survivors (those rape survivors who had received less than three psychological interventions sessions) were excluded in the target population because they would not be able to assess the effectiveness of psychological services provided to post rape survivors. This was because the new rape survivors had received few psychological interventions provided to them and therefore might have experienced insignificant reduction of psychological effects. Purposive sampling was used at the two selected centres to achieve a sample size of 44 participants. This sample was $20 \%$ of the total population of two hundred and ninety, which is in accordance to the minimum acceptable sample for a 
survey of a small population [28]. In addition, nine psychological counsellors who attended to rape survivors at the selected post-rape care centres in Kenya were key informants who also provided information that complemented that which was to be obtained from the rape survivors.

The research instruments for this study were researcher's developed structured questionnaires. The first research instrument was a questionnaire to be completed by the rape survivors who were minors aged ten to seventeen (10-17) years while the second research instrument was a questionnaire to be completed by those aged eighteen to forty five (1845) years. Key informants who were the psychological counsellors completed the third instrument. The respondents who agreed and came on the appointment date were assured of confidentiality and explained the nature of research and allowed to ask any questions for clarity. They then signed an already prepared written consent to take part in the study from each of the two-research sites. After the research instruments had been administered to the respondents by the researcher, gathered data from the questionnaires in both quantitative and qualitative forms were generated. The quantitative data obtained were edited, coded, tabulated, analysed and summarized using descriptive statistics such as means, frequencies and percentages. This was aided by Statistical Package for Social Sciences (SPSS), version 9.X. The qualitative data on the other hand was collected, recorded, and analysed thematically.

\section{RESULTS}

\section{Psychological Interventions Provided at Post-Rape Care Centres}

The objective of the study was to identify and describe the psychological interventions provided to rape survivors in post-rape care centres in Kenya. A list of psychological interventions commonly provided to rape survivors, according to literature, was provided and presented to the respondents. The rape survivors were then asked to indicate by ticking the psychological interventions received from the list as well as add any others they had encountered. The findings were as shown in Table-1.

Table-1: Psychological Interventions Provided in Post-Rape Care Centres (from Rape Survivors)

\begin{tabular}{|l|l|l|}
\hline Intervention & Frequency & Percent \\
\hline Immediate counselling & 44 & 100.0 \\
\hline Examination by a doctor & 44 & 100.0 \\
\hline HIV counselling and testing & 44 & 100.0 \\
\hline Legal services & 28 & 63.6 \\
\hline Individual counselling & 44 & 100.0 \\
\hline Family counselling & 43 & 97.7 \\
\hline Group counselling & 43 & 97.7 \\
\hline Follow-up counselling & 42 & 95.5 \\
\hline Referral to a support group & 40 & 90.9 \\
\hline
\end{tabular}

From Table-1, all $(100 \%)$ of the respondents indicated that at the post-care rape centres, they had received immediate counselling, had been examined by the doctor, tested and counselled on HIV and had received individual counselling. Moreover, a majority of the respondents indicated that they had received family counselling $(97.7 \%)$, group counselling (97.7\%), follow-up counselling (95.5\%) and referral to a support group (90.9). Lastly, many (63.6\%) of the respondents indicated that they had received legal services.

In addition to the information gathered from the survivors, data was obtained from the counsellors who were treated as key informants. Data from the latter is presented in Table-2. They were asked to list the psychological interventions they provided at their respective centres.

Table-2: Psychological Interventions Provided at Post-Rape Care Centres (from Counsellors)

\begin{tabular}{|l|l|l|}
\hline Interventions & Frequency & Percent \\
\hline Support group counselling & 8 & 88.9 \\
Post-rape trauma individual counselling & 6 & 66.7 \\
Family counselling & 6 & 66.7 \\
\hline Prevention of HIV, STI and Pregnancy & 4 & 44.4 \\
\hline Treatment of physical injuries & 1 & 11.1 \\
\hline Sheltering vulnerable survivors & 2 & 22.2 \\
\hline Follow up counselling & 2 & 22.2 \\
\hline Psychological first aid & 4 & 44.4 \\
\hline Legal aid & 4 & 44.4 \\
Life skills training & 3 & 33.3 \\
\hline Psycho-education & 3 & 33.3 \\
\hline
\end{tabular}


As shown in Table-2, majority of the counsellor respondents (88.9\%) indicated that the centres offered supportgroup counselling, $66.7 \%$ indicated that they offered post-rape trauma counselling and family counselling. Moreover, $44.4 \%$ indicated that they provided interventions geared towards preventing HIV, STI and pregnancy, as well as psychological first aid and legal aid. Only $11.1 \%$ of the respondents indicated that they offered treatment for physical injuries.

\section{The Effectiveness of Psychological Interventions}

The study also sought to assess the effectiveness of psychological interventions offered at post-rape care centres. Two methods were used to achieve this objective. The first method was by assessing the perceived level of usefulness by respondents on each psychological intervention provided. The second method was by comparing the survivors' reported level of severity of psychological effects before and after treatment. Mean severity of psychological effects before and after treatment were then computed. This was followed by a test of significance of the obtained psychological effects severity means before and after treatment. The findings were as presented in the sections below.

\section{Perceived usefulness of psychological interventions}

Data on the perceived usefulness of the psychological interventions was obtained by asking the respondents to rate the intervention's usefulness using a scale of 1 to 5 , where: $5=$ very useful, $4=$ useful, $3=$ somewhat useful, $2=$ not useful, and 1=worsened the psychological effects. A mean was calculated for the sample to indicate the level of usefulness for each intervention as well as a combined means for all the interventions. The findings for the mean individual interventions as well as that for the combined interventions were as indicated in Table 3.

Table-3: Effectiveness of Psychological Interventions Provided at Post-Rape Care Centres
\begin{tabular}{|l|l|}
\hline Intervention & Mean of the Perceived Usefulness \\
\hline Immediate counselling & 3.5 \\
\hline Examination by a doctor & 4.1 \\
\hline HIV Counselling and testing & 3.8 \\
\hline Legal services & 1.2 \\
\hline One on one counselling & 4.0 \\
\hline Family counselling & 2.8 \\
\hline Group counselling & 4.1 \\
\hline Follow-up counselling & 1.5 \\
\hline Support group & 4.4 \\
\hline Combined interventions usefulness mean & $\mathbf{3 . 3}$ \\
\hline
\end{tabular}

As per Table-3, the findings show that majority of respondents found support group most useful (Mean=4.4), followed by group counselling (Mean=4.1), examination by the doctor (Mean=4.1) and one-on-one counselling $(\mathrm{Mean}=4.0)$ as useful. Legal services (Mean=1.2), follow-up counselling (Mean=1.5) and family counselling $($ Mean=2.8) were perceived as not useful. For the combined interventions, generally, all the provided interventions were perceived to be somewhat useful (Mean=3.3).

\section{Effectiveness of psychological interventions provided to rape survivors}

The second method of assessing the effectiveness of post-rape care interventions was by comparing the level of severity of psychological effects of rape before and after treatment. The data was obtained by asking respondents to indicate the severity level of the psychological effects before and after treatment. Means were then obtained for each psychological effects of rape before and after treatment, as well as for the combined psychological effects of rape before and after treatment. The means were then compared to test for the significance of the differences.

Table-4 indicates the means of the level of severity of each psychological effects of rape experienced by respondents before and after treatment, as well as the combined mean of the level of severity of psychological effects of rape before and after treatment. 
Table-4: Means for Severity of Psychological Effects before and after Treatment

\begin{tabular}{|c|c|c|}
\hline Effect & Mean before Treatment & Mean after treatment \\
\hline Shock & 4.6 & 1.8 \\
\hline Numbness & 0.8 & 0.4 \\
\hline Embarrassment & 4.6 & 2.3 \\
\hline Sadness & 4.3 & 1.8 \\
\hline Anxiety & 4.4 & 1.6 \\
\hline Anger & 3.6 & 1.4 \\
\hline Trusting people & 1.5 & 2.1 \\
\hline Denial & 2.4 & 0.8 \\
\hline Feeling of worthlessness & 4.7 & 1.2 \\
\hline Revengeful feelings & 4.4 & 2.0 \\
\hline Difficulty in sleeping & 4.3 & 1.7 \\
\hline Experiencing terrifying dreams & 4.5 & 1.9 \\
\hline Avoiding people & 3.8 & 1.5 \\
\hline Experiencing feelings of being re-raped & 3.9 & 2.0 \\
\hline Feelings of intense fear & 4.7 & 1.6 \\
\hline Feelings of stigma & 4.6 & 1.5 \\
\hline Guilty feelings & 4.5 & 1.6 \\
\hline Loss of appetite & 4.3 & 1.3 \\
\hline Unable to control myself & 4.5 & 2.0 \\
\hline Pains & 4.7 & 1.5 \\
\hline Hate towards others & 4.7 & 2.0 \\
\hline Bitterness & 4.8 & 1.8 \\
\hline Insecurity & 4.0 & 1.4 \\
\hline Irritability & 3.3 & 1.3 \\
\hline Physical illness & 3.0 & 1.3 \\
\hline Mental instability & 2.6 & 1.1 \\
\hline Relations difficulties & 3.5 & 2.1 \\
\hline Helplessness & 4.8 & 1.6 \\
\hline Hopelessness & 4.8 & 1.5 \\
\hline Difficulties functioning sexually & 0.7 & 0.4 \\
\hline Multiple sexual partners & 0.7 & 0.4 \\
\hline Combined means before and after treatment & 3.7 & 1.5 \\
\hline
\end{tabular}

Table-4 shows that the mean of the combined psychological effects before treatment was 3.7 while after treatment was 1.5. This indicated that post-rape interventions had helped to reduce the psychological effects of rape on rape survivors. As such, it was deduced that the psychological interventions offered to rape survivors in post-rape care centres were effective.

\section{Hypothesis Test Results}

The study further sought to establish if there was any statistically significant difference between the means of the psychological effects of rape experienced by rape survivors before and after treatment. To achieve this objective, the study hypothesised that that there is no significant difference between the means of the psychological effects of rape experienced by rape survivors before and after treatment. To test this hypothesis, a paired sample t-test was conducted. A paired sample t-test was suitable for this study as the same respondents answered the same question but under different circumstances that is before and after treatment. The findings were as shown in Tables 5 and 6 .

Table-5: Paired Samples Descriptive

\begin{tabular}{|l|l|l|l|l|l|}
\hline \multicolumn{2}{|c|}{} & Mean & N & Std. Deviation & Std. Error Mean \\
\hline Pair 1 & Mean after & 1.513 & 44 & .4958 & .0891 \\
\cline { 2 - 6 } & Means before & 3.742 & 44 & 1.2777 & .2295 \\
\hline
\end{tabular}


Table-6: Paired Sample T-test

\begin{tabular}{|l|l|l|l|l|l|l|l|l|l|}
\hline \multicolumn{2}{|l|}{} & \multicolumn{9}{|l|}{ Paired Samples Test } & \multicolumn{2}{l|}{ Paired differences } & \\
\hline & & \multicolumn{9}{|l|}{ 95\% confidence interval } \\
\hline & Mean & Std. Dev. & $\begin{array}{l}\text { Std. Error } \\
\text { Mean }\end{array}$ & Lower & Upper & T & Df & Sig. (2-tailed) \\
\hline Pair 1 & $\begin{array}{l}\text { Means after -Means } \\
\text { before }\end{array}$ & -2.2290 & 1.0021 & .1800 & -25966 & -1.8615 & -12.385 & 30 & .000 \\
\hline
\end{tabular}

As shown in Table 5 and 6, a paired samples t-test was used to determine whether there was a statistically significant mean difference between psychological effects experienced before treatment and psychological effects experienced after treatment. Respondents had low mean of psychological effects experienced after treatment $(\mathrm{M}=1.513$, $\mathrm{SD}=0.4958)$ compared to the mean of psychological effect before treatment $(\mathrm{M}=3.742, \mathrm{SD}=1.2777)$, a statistically significant mean decrease of $2.229(95 \%$ CI $[-2.5966,-1.8615], \mathrm{t}(-12.385)=30, \mathrm{p}<0.01)$. This led to the rejection of the null hypothesis that there is no significant difference in the mean psychological effect before and after treatment. As such, it was concluded that there was a significant difference in the mean psychological effect before and after treatment.

\section{DISCUSSION}

\section{Psychological Interventions Provided in Post-Rape Care Centres}

The study sought to identify and describe the psychological interventions provided to rape survivors at selected post-rape care centres in Kenya. The findings showed that all of the rape survivors had received immediate counselling on arrival in the hospital, had been examined by the doctors, had received HIV counselling and testing and had received individualised counselling. This finding showed that rape survivors had been helped to deal with the acute phase effects of rape as they are undergoing short-term psychological effects. Such interventions are useful as supported by Barry [11] who found that early psychological interventions help individuals through their immediate reactions by reducing and preventing severe psychological effects. Similarly, many of the respondents indicated they had received family counselling, group counselling, follow-up counselling and referral to a support group. These interventions were in accordance with WHO standard treatment intervention protocol [9]. The study showed that post-rape care centres in Kenya were providing most of the recommended psychological interventions to rape survivors.

The finding of the study further indicated that there was provision of family counselling, group counselling, follow-up counselling and support group at post-rape care centres. This suggested that the programmes, in addition to addressing the immediate personal needs of the survivors in the acute phase, also addressed the long-term and severe psychological effects. For example, by bringing in the family, which is a core support system, the survivor is assured of a long-term support system. Similarly, the group counselling and support groups helps the survivor to gain from the therapeutic factors in a group which include installation of hope and sense of universality where they realize they are not alone in the issue. This study finding was in agreement with those of Faugno and Speck [14] who found that some rape survivors may find it difficult to cope on their own and may develop chronic and severe psychological effects, which require long-term formal psychological interventions.

Few of the respondents indicated that they had received legal services. This finding underscored the view by Population Council [10] and Kilonzo et al., [24] that there is need to establish strong links between legal and health services. The dearth of legal services could be due to poor referral systems, insufficient staff or lack of legal services, which could cause delays or long queues as reported by participants. Other interventions, like art therapy, were missing and yet majority of the rape survivors were children who could benefit best from such interventions. This finding was contrary to the provision of psychological interventions in developed countries as shown by Chapman et al., [8] that art therapy is key in helping children deal and cope with PTSD in California USA.

The WHO (2004) also states that many of psychological effects of rape could be prevented or minimized with the provision of standard protocols of interventions at post-rape care centres. Therefore, the findings of the study underlined the need for all post-rape care centres established by government or private sector to provide adequate legal services to all rape survivors as this could help in reduction of psychological effects experienced by rape survivors hence improve the overall effectiveness of psychological interventions.

\section{Effectiveness of Psychological Interventions Provided to Rape Survivors}

The study also sought to gauge the effectiveness of psychological interventions provided to rape survivors. This was measured using the perceived usefulness of psychological interventions provided and the effectiveness of psychological interventions in reducing the psychological effects of rape. 


\section{Perceived usefulness of psychological interventions}

The study found that the combined perceived usefulness of psychological interventions was somewhat useful. Therefore, the following psychological interventions provided at post-rape care centres in Kenya were perceived as useful: support group, examination by a doctor and group counselling, individual counselling, HIV counselling and testing, and immediate counselling on arrival in hospital. This implied that the psychological interventions provided were generally perceived as useful and, therefore, may have been effective in reducing psychological effects among rape survivor in post-rape care centres in Kenya. This was in agreement with findings of Feeny, Zoellner and Foa [29], who found that effective psychological interventions for rape survivors included group therapy, support group, and individual counselling.

Support group and group counselling may have been perceived useful because many rape survivors could have felt safe among other survivors, who were more understanding of the psychological effects they were undergoing. This means the groups could facilitate early psychological recovery and prevent worsening of psychological effects. Similarly, Decker and Naugle [30] found that majority of rape survivors could be more interested in immediate safety, practical group support and medical treatment.

This study finding showed that emergency interventions such as doctor's examination and HIV counselling and testing could have been effective in preventing the worsening of psychological effects of rape on the survivors. This is in agreement with Keesbury, Skibuak and Zama [31], who observed that increased access to emergency care (EC) would encourage more rape survivors to enter into the institutional support system, while at the same time directly reduced the long-term psychological and psychosocial effects of rape and hence facilitated early psychological recovery. This study finding agreed with those of Campbell and Raja [32] who found that individual counselling was identified as key in speeding the psychological recovery process.

However, the study findings showed that legal services, follow-up counselling and family counselling were perceived as not useful. This was partly in agreement with the study findings by Campbell and Raja [32] who found that rape survivors had been discouraged from reporting the rape incident due to the community general attitudes towards the rape survivors. There was a possibility that these psychological interventions were poorly organized or may have not been provided adequately to the rape survivors or they were not given family and psychological support. This could mean that the survivors may not be able to initiate or complete the legal process. Another factor that could have contributed to follow-up counselling being perceived as not being useful or not an effective psychological intervention provided to rape survivors could be due to unavailability of post-rape care centres in close proximity to the rape survivor, making it difficult or expensive for them to seek immediate counselling and follow-up care. This was because few postrape care centres have been established within the few existing health facilities in Kenya.

Ineffective psychological interventions could also be due the lack of family support in ensuring all the psychological interventions are provided to the survivors in terms of escorting and providing transport to and from postrape care centre especially the children survivors. This was in agreement with Turin [33] who found that the most significant barriers to entry in to the Kenyan health care systems are the cost of care and the unavailability of suitable care within reasonable distance. Therefore, there is need to establish more post-rape care centres in Kenya.

Family counselling was perceived as not useful yet psychological effects are not necessarily limited to the survivor but also to the family and/or partners because they also undergo trauma and require psychological counselling [34]. The study findings disagreed with those of Lovett [35] who found that maternal responses that are supportive and protective have been associated with improved mental health and functioning among rape survivors. Supportive responses from partners also have positive influences on survivor's health and predict fewer psychological effects [36]. Therefore, family members of rape survivors need to be provided with family counselling and sensitized on the importance of family support in the care of the survivor's psychological health.

Other factors that might have contributed to family and follow-up counselling being perceived as not useful could be due to insufficient number of counsellors, few counselling's rooms, and lack of capacity building for counsellors. This was in line with the view by Kilonzo and Taegtmeyer [20] that in Kenya there was need to train the staff in post-rape care centres so that they could obtain some skills on how to enhance psychological recovery. This was an indication that post-rape centres in Kenya may not be meeting staff training standards of other parts of the world, like in United States and Zambia [37, 38]. Considering the evidence that both family counselling and follow-up counselling were useful in long-term recovery for rape survivors, this study's finding underlined the fact that this area needs to be given much more attention in the post-rape centres. 
The psychological interventions provided were generally perceived somewhat useful led by support group, group counselling and individual counselling. However, the study findings showed that legal services, follow-up counselling and family counselling were perceived as not useful. There could be a possibility that these psychological interventions were poorly organized or may have not been provided adequately to the rape survivors due inadequate staff and lack of family support to facilitate attendance to these interventions. Therefore, for effective provision of psychological interventions in post-rape care centres, there is need to review the implementation of these interventions.

\section{Effectiveness of psychological interventions in reducing psychological effects}

The study further sought to establish the effectiveness of psychological interventions offered at post-rape care centres. The findings showed that there was a statistical significant difference between the mean severity level of the psychological effect before and after treatment. The study findings also showed that there was a significant difference between the combined mean of severity level of psychological effects before treatment and after treatment among rape survivors in selected post-rape care centres in Kenya. This was an indication that the severity level of psychological effects after treatment reduced from high to low after treatment showing that the rape survivors could have felt less psychological effects after treatment. It also implied that with the provision of effective psychological interventions there is an enhanced reduction of psychological effects among rape survivors, that minimizes the chances of developing longterm psychological effects. The study findings were in agreement with Astbury and Jewkes [6] who found that longlasting psychological effects of rape on survivors would be prevented or reduced with the provision of psychological interventions at post-rape care centres.

It could also imply that the rape survivors had developed new coping skills learned during treatment to cope with psychological effects. The findings agreed with the views by Caplan [39], in his Crisis Theory, that when an individual faces a stressful situation that is not possible to be solved through utilization of already learned methods of problem solving, the person mobilized internal and external resources to solve and reduce the painful state of stress. In this study, the psychological intervention could have helped reduce the severity of the psychological effects.

The following individual psychological effects scored high on mean severity level of psychological effects before and after treatment: hopelessness and bitterness reduced. Difficulties functioning sexually and multiple partners scored low on mean severity level of psychological effects before treatment. This could mean that the high mean severity level of psychological effect experienced by rape survivors before treatment showed a reduction in mean severity level after treatment as indicated by scores. These findings corresponded with the views by Fassler et al., [40] that psychological effects could be minimized at any stage of development if the rape survivor constructively coped with the stressful situation, with the help and support from other persons.

In the study, none of the psychological effects showed no reduction of the level of severity after treatment. This could indicate majority of the rape survivors could have been able to develop new problem solving skills. This findings differed with the position by Frazier [41] that individuals who fail to grow from the crisis experienced or fail to developed new problem-solving skills go on to develop psychotic patterns of behaviour such as having distorted perceptions, withdrawal, becoming suspicious, depressed, drinking excessively or abused drugs.

The study findings indicated that, overall, the psychological interventions reduced the psychological effects of rape on survivors. This agreed with the position of the US National Centre for PTSD [42] that many rape survivors recovered from the psychological effects of rape, through early identification and treatment of psychopathology. A study by Barry [11] also agreed with the current study, which showed that early psychological interventions of helping individuals through their initial reactions to assault reduced or even prevented more severe psychological distress. This implies that psychological interventions are essential component of effective interventions provided to rape survivors. This could be because effective psychological interventions prevented long-term psychological effects of rape on the rape survivor.

The study findings showed that the psychological interventions help reduce the severity of the psychological effects experienced by rape survivors. This finding supported the suggestion by the WHO [9] that many of the harmful and lasting psychological effects of rape could be prevented or minimized with structured interventions and the provision of psychological interventions at post-rape care centres. Therefore, reduction of psychological effects could enhance psychological recovery and prevents worsening of psychological effects. This means that the psychological interventions offered at post-rape care centres in Kenya may have had a positive impact, thus there were significant difference between the mean severity level of psychological effects experienced before and after treatment. This means that the psychological interventions may have reduced the psychological effects of rape among survivors. Therefore, there is a possibility that improvement in the effectiveness of all the psychological interventions provided to rape survivors could minimize the worsening of psychological effects. 


\section{CONCLUSION}

From the study findings, the study concluded that most of the psychological interventions provided at post-rape care centres in Kenya are in line with standard protocol administered internationally. However, the post-rape care centres do not offer adequate legal services to all the rape survivors. The study also established that there is significant difference in the severity levels of psychological effects before and after treatment. The severity of psychological effects before treatment are higher compared with the psychological effects after treatment. This means that, overall, the psychological interventions provided at post-rape care centres in Kenya are somewhat useful in reducing and preventing worsening of the psychological effects of rape on survivors.

\section{RECOMMENDATIONS}

Based on the study findings and conclusion, it is recommended that, to improve the overall effectiveness of psychological interventions provided to rape survivors in post-rape-care centres, there should be a review of the interventions provided to ensure adequate provision especially of the legal services, follow-up and family counselling. Moreover, to enhance the effectiveness of psychological interventions provided to rape survivors at post-rape care centres beyond the current perceived somewhat useful level in reducing the severity of psychological effects, the implementers should adhere to all the recommended interventions by the program developers.

\section{REFERENCES}

1. Jewkes, R., Sen P., \& Garcia-Moreno, C. (2002). Sexual violence. In E. Krug, L. Dahlberg, J. A. Mercy, A. B. Zwi, \& R. Lozano, (Eds.), World report of violence and health. Geneva: World Health Organization.

2. Vickerman K. A., \& Margolin, G. (2009). Rape Treatment Outcome Research: Empirical Finding and the state of the literature. Clinical Psychology Review, 29, 431448.

3. McNally, R. J., Bryant, R. A., \& Ehlers, A. (2003). Does early psycho- logical intervention promote recovery from posttraumatic stress? Psychological Science in the Public Interest, 4(2), 45-79.

4. Keesbury, J., Askew, I., Wanjiru, M., Chiyaba, G., Wilson, K., \& Simmonds, F. N. (2011). Comprehensive Responsive Responses to sexual violence in Eastand Southern Africa: Lessons Learned from Implementation. Lusaka: Population Council.

5. Campbell, R., Sefl, T., Barnes, H. E., Wasco, S. M., \& Ahrens, C. E. (2001). Preventing the "Second rape". Rape survivors' experiences with community service providers. Journal Interpersonal Violence, 16, 1339-1359.

6. Astbury, J., \& Jewkes, R. (2011). Sexual Violence. Routledge: Handbook of Global Public.

7. Jaycox, L. H., Zoellner, L., \& Foa, E. B. (2002). Cognitive-behavioural therapy for PTSD in rape survivors. Journal of Clinical Psychology, 58, 891-906.

8. Chapman, L., Morabito, D., Ladakakos, C., Schreier, H., \& Knudson, M. M. (2001). The effectiveness of art therapy interventions in reducing post traumatic stress disorder (PTSD) effects in Paediatric trauma patients. Art Therapy, 18(2), 100-104.

9. World Health Organization (WHO). (2004). Preventing Violence: A Guide to Implementing the Recommendations of the World Report on Violence and Health. Geneva: WHO.

10. Population Council. (2008). Sexual and gender based violence in Africa Literature review. Nairobi. Kenya: Population Council, Inc.

11. Barry L. (2006). Sexual Assault: Clinical Issues: SANE expert and factual testimony. Journal of Emergency Nursing, 24(3), 284-287.

12. Resnick, H., Acierno, R., Kilpatrick, D. G., \& Holmes, M. (2005). Description of an Early Intervention to Prevent Substance Abuse and Psychopathology in Recent Rape Victims. Behaviour Modification, 29, 156-188.

13. Atkinson, R. (1998). The Life Story Interview. Thousand Oaks, California: Sage.

14. Faugno, D., \& Speck, P. (2001). Sexual Assault: Clinical Issues. SANE: Advocate, forensic technician, nurse? Journal of Emergency Nursing, 27(1), 91-93.

15. Joint Commission on Accreditation of Health Organizations (JCAHO). (2006). Comprehensive Accreditation Manual for Hospitals: The Official Handbook. Oakbrook Terrace, III: Joint Commission on Accreditation of Health Care Organization.

16. National Centre for PTSD. (2005). Frequently asked questions about PTSD assessment. Retrieved September 2, 2005 from http://www.ncptsd.va.gov/facts/specific/fs_assessment_FAQs.html

17. Netzel, L. (2003). Forensic Nursing: DNA evidence collection. Journal of Emergency Nursing, 23(2), $182-186$.

18. Keesbury, J., \& Askew, I. (2010). Comprehensive responses to gender based violence in low-resource settings: Lessons learnt from implementation. New York, NY: Population Council.

19. USAID. (2006). Strengthening Regional Work on Gender-Based Violence. Diana de Filippi and Nancy Rosenfeld.

20. Kilinzo, N., \& Taegtmeyer, M. (2005). Comprehensive Post-Rape Care Services in Resource-poor setting: Lessons learnt from Kenya. Liverpool School of Tropical Medicine. Nairobi, Kenya, Liverpool VCT Kenya. Policy Briefing for Health Sector Reform: No. 6th September 2005. 
21. Ellis, C. D. (2002). Male rape - the silent victims. Collegian, 9(4), 34-39.

22. Maternowska, C., Keesbury, J., \& Kilonzo, N. (2009). Sexual Violence: Setting the research agenda for Kenya. Nairobi, Kenya: Population Council.

23. Liverpool, V. C. T. (2005). Comprehensive Post-Rape Care Services in Resource-poor setting: Lessons learnt from Kenya.

24. Kilonzo, N., Theobald, S. J., Nyamato, E., Ajema, C., Muchela, H., Kibaru, J., Rogena, E., \& Taegtmeyer, M. (2008). Engendering Health Sector Response to Sexual Violence and HIV in Kenya. Nairobi, Kenya.

25. Gender Violence Recovery Centre. (2008). Support to the Gender Violence Recovery Centre, annual reports, April 2007 till March 2008, Nairobi Women's Hospital. Nairobi, Kenya: GVRC.

26. Onyango-Ouma, W., Ndung'u, N., Barasa, N., \& Birungi, H. (2009). The making of Kenya sexual violence act, 2006: Behind the scene. Nairobi: Kwani Trust.

27. Said Said, H., Awori, K. O., \& Odula, P. (2008). Gender-associated violence at a women's hospital in Nairobi, Kenya. East African Medical Journal, 85(7), 347-54.

28. Gay, L. (1992). Educational research: Competencies for Analysis and Application (4 ${ }^{\text {th }}$ ed.). New York: Mc Millan.

29. Feeny, N. C., Zoellner, L. A., \& Foa, E. B. (2002). Treatment outcome for chronic PTSD among female assault victims with borderline personality characteristics: A preliminary examination. Journal of Personality Disorders, 16, 30-40.

30. Decker, S. E., \& Naugle, A. E. (2009). Immediate Intervention for Sexual Assault: A Review with Recommendations and Implications for Practitioners. Journal of Aggression, Maltreatment and Trauma, 18(4), 419441.

31. Keesbury, J., Skibuak, J., \& Zama, M. (2006). Reducing unwanted pregnancy among victims of sexual violence assault: New windows of opportunity for emergency contraception. Draft paper. Lusaka, Zambia: Population Council.

32. Campbell, R., \& Raja, S. (2005). The sexual assault and secondary victimization of female veterans: Help-seeking experiences in military and civilian social systems. Psychology of Women Quarterly, 29, 97-106.

33. Turin, D. (2010). Health Care Utilization in the Kenyan Health System: Challenges and Opportunities. Student Pulse, 2(09). Retrieved from http://www.studentpulse.com/a?i=284

34. Medical Research Council (2009). Shattered Lives: Immediate Medical Care Vital for Sexual Violence Victims. Brussels: Medecins San Frontieres.

35. Lovett, B. B. (2004). Child sexual abuse disclosure: Maternal response and other variables impacting the victim. Child and Adolescent Social Work Journal, 21, 355-371.

36. Jonzon, E., \& Lindblad, F. (2005). Adult female victims of child sexual abuse: Multiple maltreatment and disclosure characteristics related to subjective health. Journal of Interpersonal Violence, 20, 651-666.

37. Ledray, L. E. (1999). The Sexual Assault Nurse Clinician: Minneapolis' 15 Years' Experience. Journal of Emergency Nursing, 18(3), 217-221.

38. Afrique, E. C. (2004, May 22). EC and care for sexual assault. Afrique Bulletin, vol. 2/2. Retrieved from https://www.cecinfo.org/wp-content/uploads/2013/03/Population-Council-ECAfrique-Sexual-Assault-EnglishFrench.pdf

39. Caplan, G. (1964). Principles of Preventive Psychiatry. New York: Basic Books.

40. Fassler, I. R., Amodeo, M., Griffin, M. L., Clay, I. R., \& Ellis, M. A. (2005). Predicting long-term outcomes for women sexually abused in childhood: Contribution of abuse severity versus family environment. Child Abuse \& Neglect, 29, 269-284.

41. Frazier, P. A. (2003). Perceived control and distress following sexual assault: A longitudinal test of a new model. Journal of Personality \& Social Psychology, 84, 1257-1269.

42. US National Centre for PTSD. (2007). Trauma, PTSD, and the Primary Care Provide. Retrieved August 2, 2010 from http//www.pstd.va.gov/professional pages/trauma-ptsd-and provider.Asp. 